\title{
IMPACT OF NON-INVASIVE VENTILATION IMMEDIATELY AFTER EXTUBATION ON CLINICAL AND FUNCTIONAL OUTCOMES IN PATIENTS SUBMITTED TO CORONARY ARTERY BYPASS GRAFTING: CLINICAL TRIAL
}

\author{
André Luiz Lisboa Cordeiro ${ }^{1}$, Carolina Silva ${ }^{1}$, Mayana Santana ${ }^{1}$, Kênia Lima ${ }^{1}$, André \\ Guimarães $^{2}$, and Patrícia Forestieri ${ }^{3}$ \\ ${ }^{1}$ Faculdade Nobre \\ ${ }^{2}$ Instituto Nobre de Cardiologia \\ ${ }^{3}$ Federal University of São Paulo
}

December 16, 2020

\begin{abstract}
Introduction: The application of non-invasive ventilation(NIV) after coronary artery bypass grafting(CABG) brings the possibility of reducing loss of functional capacity and complications in the patient. However, the evidence is controversial about immediate or conventional use. Objective: Assess the impact of immediate NIV after extubation on oxygenation and functional capacity of patients undergoing to CABG. Methods: Randomized clinical trial. Patients were assessed before and after surgery using the Functional Independence Measure(FIM), six-minute walk test(6MWT) and peripheral muscle strength(MRC). On the first day after the surgery, two groups formed immediate NIV(NIVI) and conventional NIV(NIVC). Hemogasometry was collected before and after NIV. Complication rates were also assessed. NIVI performed ventilation after one hour of orotracheal extubation, at NIVC performed NIV on the first postoperative day, 24 hours after extubation. After discharge, the above variables were reevaluated. Results: 79 patients were evaluated, 46(58.22\%) men, mean age $65 \pm 9$ years. NIVI reduced the reintubation rate, only $1(3 \%)$ compared to NIVC with $5(12 \%)$ patients, $\mathrm{p}=0.01$. In the post-Intervention the inspired oxygen fraction ( $\mathrm{FiO} 2$ ) was $0.43 \pm 0.07$ in the conventional group and $0.30 \pm 0.10$ in the intervention group, $\mathrm{p}=0.01$. The post-intervention $\mathrm{PaO} 2 / \mathrm{FiO} 2$ ratio was $191 \pm 45$ and NIVI $266 \pm 29(\mathrm{p}<0.001)$ and one day later in the NIVC it was $210 \pm 39$ and NIVI $279 \pm 37(\mathrm{p}$ $<0.001)$. VNII lost $51 \pm 36$ meters in the $6 \mathrm{MWT}$ compared to the NIVC that lost $95 \pm 40$ meters(p <0.01). Conclusion: NIVI after extubation of patients undergoing to CABG, reduced the loss of functional capacity, improved blood gases and decreased the rate of reintubation.
\end{abstract}

\section{INTRODUCTION}

Cardiac surgery (CS) is a widely used treatment process due to the high incidence of cardiovascular disease worldwide ${ }^{1}$. Among the most common surgeries, coronary artery bypass grafting (CABG) stands out, a procedure that improves the quality of life of patients with symptomatic myocardial ischemia, when one or more coronary arteries are obstructed by atheroma plaques leading to a decrease in blood flow to the heart muscle $^{2}$. Patients undergoing CABG show significant results, but the vast majority develop postoperative pulmonary disorders ${ }^{3}$.

After surgery, there is a decrease in ventilatory muscle strength and pulmonary function, causing a negative impact on these patients ${ }^{4}$. Thus, the appearance of pulmonary complications can cause unfavorable clinical outcomes such as atelectasis, pneumonia, pulmonary edema and acute respiratory failure (ARF), favoring 
negative functional results ${ }^{5,6}$. Some factors such as age, overweight, sex, type of surgery and intraoperative conditions can contribute to the development of these complications ${ }^{7}$.

Noninvasive ventilation (NIV) can be used right after extubation in order to minimize pulmonary dysfunction, reduce the length of stay in the intensive care unit (ICU) and represent an improvement in the functional capacity of these patients ${ }^{8,9,10,11}$. According to the mechanical ventilation (MV) guideline, NIV should be performed immediately after extubation, however in some services it appears on the first postoperative day as the institution's protocol ${ }^{12}$. There is still little evidence for validation in relation to clinical and functional outcomes if NIV immediately after extubation may be more appropriate when compared to that performed in the first postoperative day.

Despite being a recommendation of Brazilian guidelines, the application of NIV immediately after extubation is not yet a reality in most ICUs. Therefore, this work can confirm the importance of this therapy in patients undergoing $\mathrm{CABG}^{12}$. The purpose of this study was to compare the clinical and functional impact of two postextubation (or prophylactic) non-invasive mechanical ventilation protocols for patients undergoing coronary artery bypass graft surgery.

\section{METHODS}

\section{Study Design}

This is a randomized controlled clinical trial conducted with the group of patients admitted to the Intensive Care Unit at the Instituto Nobre de Cardiologia (INCARDIO) in Feira de Santana - BA, from January 2016 to October 2019. The study was approved by the Research Ethics Committee of Faculdade Nobre de Feira de Santana - Bahia, under opinion number 1,405,821. All patients were informed about the objectives of the study and signed a free and informed consent form.

\section{Eligibility Criteria}

This study included patients of both sexes, aged 18 years or older and who underwent to coronary artery bypass grafting with median sternotomy and cardiopulmonary bypass. Patients with hemodynamic instability before noninvasive ventilation, who were not cooperative or who had contraindications for the use of NIV, chronic pulmonary disease, absence of blood gas analysis in some of the study phases, physical limitations that compromised the performance of functional tests were excluded (amputation), difficulty understanding to perform the applied tests, surgical reintervention, more than 24 hours in invasive mechanical ventilation and patients who refused to sign the consent form.

\section{Outcomes}

The primary outcome was oxygenation and functional capacity. The secondary was the impact on functional variables such as Functional Independence Measure (FIM), peripheral muscle strength, pulmonary complications, death, length of stay in the ICU and hospital. The primary oxygenation outcome was assessed before, immediately after, and one day after NIV application, functional capacity was assessed preoperatively and on the day of hospital discharge. Secondary outcomes were assessed preoperatively and on the day of hospital discharge.

\section{Study protocol}

In the preoperative moment, all patients were functionally assessed using the FIM, six-minute walk test and peripheral muscle strength through the Medical Research Council (MRC).

The next day the patients were referred to the operating room. The surgery took place with the same surgical team, being performed via median sternotomy and cardiopulmonary bypass, using the graft of the external thoracic artery or bypass. All patients left the operating room with a subxiphoid and intercostal drain and were referred to the ICU with full analgesia. Upon arriving at this unit, they were conducted according to routine, with no influence from the researchers. In accordance with the weaning criteria, the patients were 
guided and, subsequently extubated, oxygen support at low flow was started, with a percentage sufficient to maintain saturation between 94 and $97 \%$.

In the hospital where the research was carried out, NIV is routinely performed on the first postoperative day. Shortly after extubation, eligible patients were randomized using the electronic system: http://randomizer.org/form.htm, performed by a professional not belonging to the research group, and this procedure was kept confidential from other members of the search. Sealed, opaque and sequentially numbered envelopes were used to hide the allocation sequence until interventions were designated. The researchers responsible for the evaluations were blinded to the intervention and control groups.

Patients were divided into two groups: immediate NIV group (NIVI) and conventional NIV group (NIVC). The NIVI group performed noninvasive ventilation immediately after orotracheal extubation, whereas the NIVC group performed NIV on the first postoperative day around 24 hours after extubation.

NIV was performed on the Servo-S ventilator (Dräger Medical, Lübeck, Germany) in ventilation mode with support pressure, the pressure being sufficient to maintain the tidal volume between 6 to $8 \mathrm{ml} / \mathrm{kg}$, positive pressure at the end of expiration starting at $5 \mathrm{cmH} 2 \mathrm{O}$, reaching $12 \mathrm{cmH} 2 \mathrm{O}$ and inspired oxygen fraction of $30 \%$. A face mask was used and the increase in PEEP was protocol, occurring in all patients. This therapy was maintained for 40 minutes in both groups and performed only once. An arterial blood gas analysis was collected before and after NIV for analysis of gas behavior. A day later, a new blood gas analysis was collected for late verification of oxygenation.

On the day of discharge from the ICU, patients were again evaluated for MIF, MRC and analyzed for pulmonary complications, deaths and length of stay in that unit. These assessments were repeated on the day of hospital discharge, adding up to the repetition of the six-minute walk test. All patients received standard assistance from the physiotherapy service, which consisted of kinesiotherapy, cycle ergometry and walking.

The outcomes related to postoperative complications were assessed by a radiologist who was blind. Gasometric and functional evaluation were performed one by a blind doctor and physiotherapist, respectively.

\section{Measuring Instruments}

The six-minute walk test was used following the recommendations of the American Thoracic Society (ATS) and was performed in a 30-meter corridor, flat and completely free of obstacles ${ }^{13}$. Before the test, patients had a rest period of at least 10 minutes. During this period, contraindications, blood pressure data (using the Premium Aneroid sphygmomanometer and Littmann 3M( stethoscope), pulse oximetry (Pulse Oximeter - Rossmax@), dyspnea level (Borg Scale), heart rate (assessed through palpation of the radial artery and counting over a period of one minute) and respiratory (evaluation by checking the respiratory incursion over the period of one minute). The patient was instructed to walk as fast as possible, without running, going around this corridor for six minutes. During the test, phrases of encouragement were used in periods of time. At the end of the test, the examiner has the function of quantifying the meters covered within those six minutes.

During the entire protocol, the patient was monitored and, with an increase in systolic and / or diastolic blood pressure greater than $30 \%$ of baseline, heart rate below $20 \%$ of baseline, peripheral oxygen saturation $<90 \%$ and increased respiratory rate above 30 forays per minute the test would be interrupted.

The Functional Independence Measurement that aims to measure what the person really accomplishes, regardless of the diagnosis, generating valid score for limitation or not. This scale assesses the patient's ability to develop body care, sphincter control, transfer and locomotion, as well as cognitive function such as communication and memory. A score of 1 to 7 is assigned, with the lowest value corresponding to the patient totally dependent and the maximum value was that patient completely independent from the functional point of view, reaching a maximum value of 126 points when all variables were added together ${ }^{14}$.

The Medical Research Council (MRC), evaluates peripheral muscle strength through the ability to overcome 
the load of six muscle groups (shoulder abductors, elbow flexors, wrist extensors, hip flexors, knee extensors and ankle dorsiflexors), scoring bilaterally each group from 0 to 5 , where zero represents absence of contraction and five the patient wins the maximum resistance imposed by the examiner. The minimum score for this test is 0 (quadriplegia) and can reach up to 60 points (muscle strength preserved). A value less than 48 can be suggestive of polyneuromyopathy ${ }^{15}$.

\section{Sample Size}

The study was conducted with a convenience sample.

\section{Statistical analysis}

For data analysis, the Statistical Package for Social Sciences (SPSS) version 20.0 was used. Normality was analyzed using the Shapiro-Wilks test. Categorical variables were verified using the Chi-square. Continuous data were expressed as mean and standard deviation. To assess the oxygenation, functional and length of stay, intra and intergroup, the paired Student's t-test and the independent test were used, respectively. The variables pulmonary complications and mortality were assessed using the Chi-square. A p $<0.05$ was considered significant.

\section{RESULTS}

During the research period, 101 patients were admitted for cardiac surgery, of these 22 were excluded for the following reasons: 03 required surgical reintervention before extubation, 10 remained on mechanical ventilation for more than 24 hours, 5 refused to participate in the research, 2 were death before extubation and 1 it was not possible to collect blood gas data before NIV (Figure 1). Thus, 79 patients were studied, with no loss of follow-up after randomization, 42 were allocated to the conventional NIV group and 37 to the group immediately after extubation.

Table 1 shows the clinical and surgical characteristics of the patients. Among these, the male gender prevailed with 46 patients $(58.22 \%$ ), with a mean age of $65 \pm 9$ years, with arterial hypertension being the most prevalent comorbidity. The other variables are shown in table 1.

Significance was verified in $\mathrm{FiO} 2$ and in the $\mathrm{PaO} 2 / \mathrm{FiO} 2$ ratio. The FiO2 variables in the post-intervention, in the conventional group, it had $0.43 \pm 0.07$ and in the intervention group $0.30 \pm 0.10$, with a p-value of 0.01. With regard to $\mathrm{FiO} 2$ one day later, the conventional group had $0.40 \pm 0.09$ and in the intervention group $0.30 \pm 0.05$, with a p-value of 0.04 . The value of the $\mathrm{PaO} 2 / \mathrm{FiO} 2$ ratio in the intervention group was higher $95 \%$ CI $75(+45$ to +91$)$ right after NIV and one day later $69(95 \% \mathrm{CI}+33$ to +82$)$. The other values are shown in table 2 .

Table 3 shows the functional outcomes between the groups studied, at different times of the research. FIM and MRC did not show any statistically significant variation when comparing the groups and the preoperative period with hospital discharge, but there was a significant reduction when analyzing the preoperative and discharge from the ICU. The group of patients who underwent immediate NIV presented better performance on the $6 \mathrm{MWT}$, loss of $51 \pm 36$ meters, when compared to the conventional group that had a loss in the distance covered of $95 \pm 40$ meters $(\mathrm{p}<0.01)$. In the $6 \mathrm{MWT}$ the difference between the groups was $44(95 \%$ CI +25 to +59$)$.

Regarding post-surgical pulmonary complications, Table 4 shows the result between the groups. The only variable that obtained statistical significance was reintubation, resulting from 5 patients who underwent NIV one day after extubation and 1 who underwent NIV immediately after extubation $(\mathrm{p}=0.01)$.

\section{DISCUSSION}

Noninvasive ventilation performed immediately appeared as an effective resource in decreasing the loss of functional capacity, the rate of reintubation, improvement of oxygenation up to one day after its completion and reduction of hospital stay in patients undergoing coronary artery bypass grafting. 
In our study, patients who underwent immediate NIV presented a reduction in the loss of functional capacity, as evidenced by the distance covered in the $6 \mathrm{MWT}$, a similar result was verified by Araújo-Filho et al. ${ }^{16}$ in patients in the postoperative period of valve replacement. Possible justification for this decrease is due to the meta-reflex. The realization of NIV increases pulmonary capacity and oxygenation, thus attenuating the metaborreflex causing improvement in the perfusion of peripheral muscles, causing an increase in functional performance $^{17-19}$.

Performing the 6MWT raises the patient's metabolic rate, requiring greater blood flow to the peripheral muscles. The muscle fibers recruited during the $6 \mathrm{MWT}$ are type I, that is, it depends on oxygen, so when better lung function and greater blood flow rich in oxygen, the better the functional capacity of these patients. In the present study, the difference in the $6 \mathrm{MWT}$ was 44 meters between the conventional and immediate groups. Gremeaux et al. ${ }^{20}$ show that the difference in the 25 -meter result becomes clinically important for this patient profile.

Another fundamental point in this discussion is that NIV tends to improve the performance of the left ventricle, optimizing cardiac output and improving tissue perfusion ${ }^{21}$. This contributes to improving the functional capacity of these patients. It is important to understand that the application of NIV immediately after extubation is a resource that optimizes lung function, but the improvement in performance in the walking test can be achieved with an increase in cardiovascular function and peripheral muscles. Probably the second did not influence the result since there was no difference in the groups' MRC. There is a need to verify, through echocardiogram, myocardial behavior such as ejection fraction, stroke volume and ventricular mass.

Shoji et al. ${ }^{22}$ found a high rate of reintubation among patients undergoing cardiac surgery. They attribute this result to comorbidities such as hypertension and diabetes mellitus and to complications such as pneumonia and renal dysfunction. Therefore, our study brings NIV immediately, as a preventive factor for these complications, reducing the risk of extubation failure.

According to Wu et al. ${ }^{23}$ the role of NIV remains controversial, since the rate of reintubation does not present a significant difference, however, some authors indicate immediate NIV to avoid complications and reduce hospital stay ${ }^{24,25}$. One possibility for the divergent results is the fact that the duration of the application of NIV, the selection of patients and the protocols performed.

According to the Brazilian guideline on mechanical ventilation, the use of NIV is indicated in obese, elderly and patients with more than one comorbidity ${ }^{12}$. As a result, we realized that the patients in our study were older, overweight and had two or more comorbidities, with satisfactory results after using immediate NIV, being able to reduce the reintubation rate.

Liu et. al ${ }^{26}$ in their study show that the prophylactic use of NIV significantly reduced the rate of postsurgical complications, also showing improvement in gas exchange. The immediate use of NIV significantly reduced the rate of atelectasis in our study. The main effect of positive pressure at the end of expiration during NIV is to reopen collapsed alveoli and keep the lung aerated. This reversal of alveolar collapse tends to improve the ventilation / perfusion ratio, generating an increase in gas exchange, which was found in the present study.

In addition, it is worth noting a higher $\mathrm{PaO} 2$ / FiO2 ratio in patients who underwent immediate NIV even after 24 hours of the intervention. Despite the lack of significance in arterial oxygen pressure, recruitment of the alveoli generated less need for supplemental oxygen, which reflected in the relationship between the effectiveness of gas exchanges.

This way, it was possible to keep the patient with oxygenation level for a longer time, with a lower O2 supply and decreasing the toxicity related to the use of this gas. Therefore, in line with our result, Landoni et al. ${ }^{17}$ demonstrate that noninvasive ventilation seems to be a useful tool to decrease respiratory work, reduce atelectasis, prevent respiratory failure and improve gas exchange.

According to Laizo et al. ${ }^{27}$, complications related to respiratory function are the main causes to increase the 
length of hospital stay. Since in our study the rate of respiratory complications was low, in the group that performed NIV immediately after extubation, it may be a justification for reducing the length of hospital stay. This decrease can contribute to lower hospital costs and as a preventive factor for future complications associated with prolonged hospital stay, such as infections and loss of muscle mass.

Systematic reviews found that immediate NIV did not achieve a significant result in terms of length of stay in the ICU or hospital ${ }^{17,28}$. This can be justified by the profiles of the patients studied, who had low ejection fractions, hypoactivity and important deficits in muscle strength associated with heart failure. Contrary to our study, the patients evaluated did not present any hemodynamic instability before NIV, did not need surgical reintervention and mainly obtained positive results on the functionality scale.

One of the limitations of this study is the fact that it did not present the sample calculation, which would be effective for reaching a conclusion with a lower percentage of error. Other limitations were the fact that the study did not use a scale to assess patients' pain level, such as Visual Analogue Scale (VAS), where through it the patient can present the degree of pain at the moment and the absence of a blind examiner for variables as blood gas analysis.

\section{CONCLUSION}

Noninvasive ventilation immediately after extubation of patients undergoing coronary artery bypass grafting had a significant impact, such as reducing the loss of functional capacity, decreasing the rate of reintubation and improving blood gases, FIO2 and the $\mathrm{PaO} 2$ / FIO2 ratio.

\section{REFERENCES}

1. Daltro FMS, de Seixas Rocha M, Oliveira L. Eficácia da pressão expiratória positiva sobre a capacidade vital de pacientes submetidos a revascularização do miocárdio. Rev Bras Fisioter. 2010;14(S1):450.

2. Ataide AA, Ferraz LA, Rocua LSO, Falcão LFM, Normando VMF, Avila PES et al. Efeitos da ventilação mecânica não invasiva sobre a função pulmonar em pacientes no pós-operatório de cirurgia de revascularização do miocárdio. PRMJ 2017;1(1):1-7.

3. Renault J , Costa-Val R, RossettI M. Respiratory physiotherapy in the pulmonary dysfunction after cardiac surgery. Braz J Cardiovasc Surg 2008;23(4):562-569.

4. Cordeiro ALL, Carvalho S, Leite MC, Vila-Flor A, Freitas B, Sousa L et al. Impact of Lung Expansion Therapy Using Positive End-Expiratory Pressure in Mechanically Ventilated Patients Submitted to Coronary Artery Bypass Grafting. Braz J Cardiovasc Surg 2019;34(6):699-703.

5. Pieczkoski SM, Margarites AGF, Sbruzzi G. Noninvasive ventilation during immediate postoperative period in cardiac surgery patients: systematic review and meta-analysis. Braz J Cardiovasc Surg 2017;32(4):301311.

6. Borges DL, Nina VJS, Costa MAG, Baldez TEP, Santos NP, Lima IM et al. Effects of different PEEP levels on respiratory mechanics and oxygenation after coronary artery bypass grafting. Braz J Cardiovasc Surg 2013;28(3):380-385.

7. Ferreira LL, Souza NMD, Vitor ALR, Bernardo AFB, Valenti VE, Vanderlei LCM. Ventilação mecânica não-invasiva no pós-operatório de cirurgia cardíaca: atualização da literatura. Braz J Cardiovasc Surg 2012;27(3):446-452.

8. Esquinas AM, Gill H, Mina B. Postoperative noninvasive ventilation in patients undergoing coronary artery bypass grafting: a small step with great repercussions. J Thorac Cardiovasc Surg. 2013;146(5):1299.

9. Méndez VMF, Oliveira MF, do Nascimento BA, Xavier PA, Gun C, Sperandio PA et al. Hemodynamics and tissue oxygenation effects after increased in positive end-expiratory pressure in coronary artery bypass surgery. Arc Physioth 2017;7(1):1-5. 
10. Esquinas AM, De Santo LS. Noninvasive Ventilation after Surgical Myocardial Revascularization for Left-Ventricular Dysfunction: A Hypothesis-Generating Study. Resp Care 2019;64(1):115-116.

11. Guizilini S, Viceconte M, Esperança GT, et al. Pleural subxyphoid drain confers better pulmonary function and clinical outcomes in chronic obstructive pulmonary disease after off-pump coronary artery bypass grafting: a randomized controlled trial. Rev Bras Cir Cardiovasc . 2014;29(4):588-594. doi:10.5935/16789741.20140047.

12. Barbas CV, Isola AM, Farias AM, Cavalcanti AB, Gama AMCDA. Diretrizes brasileiras de ventilação mecânica. Associação de Medicina Intensiva Brasileira e Sociedade Brasileira de Pneumologia e Tisiologia. Parte 2. J Bras Pneumol São Paulo. 2013;1-140.

13. ATS Committee on Proficiency Standards for Clinical Pulmonary Function Laboratories. ATS statement: guidelines for the six-minute walk test. Am J Respir Crit Care Med. 002;166(1):111-7.

14. Riberto M, Miyazaki MH, Jucá SSH, Sakamoto H, Pinto PPN, Battistela LR. Validação da versão brasileira da medida de independência funcional. Acta Fisiatr. 2004;11(2):72-6.

15. Medical Research Council. Aids to the Investigation of Peripheral Nerve Injuries. War Memorandum (revised 2nd edition). London: HMSO, 1943.

16. De Araújo-Filho AA, de Cerqueira-Neto ML, Cacau LA, Oliveira GU, Cerqueira TC, de Santana-Filho VJ. Effect of prophylactic non-invasive mechanical ventilation on functional capacity after heart valve replacement: a clinical trial. Clinics 2017;72(10):618-623.

17. Landoni G, Zangrillo A, Cabrini L. Noninvasive ventilation after cardiacand thoracic surgery in adult patients: a review. J Cardiothorac Vasc Anesth. 2012;26(5):917-22.

18. Reis HV, Borghi-Silva A, Catai AM, Reis MS. Impact of CPAP on physical exercise tolerance and sympathetic-vagal balance in patients with chronic heart failure. Braz J Phys Ther. 2014;18(3):218-27.

19. Franco AM, Torres FC, Simon IS, Morales D, Rodrigues AJ. Avaliação da ventilação não-invasiva com dois níveis de pressão positiva nas vias aéreas após cirurgia cardíaca. Rev Bras Cir Cardiovasc. 2011;26(4):582-90.

20. Gremeaux V, Troisgros O, Benaïm S, Hannequin A, Laurent Y, Casillas JM et al. Determining the minimal clinically important difference for the six-minute walk test and the 200-meter fast-walk test during cardiac rehabilitation program in coronary artery disease patients after acute coronary syndrome. APMR 2011;92(4), 611-619.

21. Nasrala MLS, Bolzan DW, Lage YG, et al. Extended-time of Noninvasive Positive Pressure Ventilation Improves Tissue Perfusion after Coronary Artery Bypass Surgery: a Randomized Clinical Trial. Braz J Cardiovasc Surg. 2018;33(3):250-257. doi:10.21470/1678-9741-2017-0232.

22. Shoji CY, Figuereido LCD, Calixtre EM, Rodrigues CDA, Falcão ALE, Martins PP et al. Reintubação de pacientes submetidos à cirurgia cardíaca: uma análise retrospectiva. Rev Bras Ter Intensiva 2017;29(2):180187.

23. Wu Q, Xiang G, Song J, Xie L, Wu X, Hao S et al. Effects of non-invasive ventilation in subjects undergoing cardiac surgery on length of hospital stay and cardiac-pulmonary complications: a systematic review and meta-analysis. J Thorac Dis 2020;12(4):1507.

24. Zarbock A, Mueller E, Netzer S, Gabriel A, Feindt P, Kindgen-Milles D. Prophylactic nasal continuous positive airway pressure following cardiac surgery protects from postoperative pulmonary complications: a prospective, randomized, controlled trial in 500 patients. Chest 2009;135(5):1252-1259.

25. Cordeiro ALL, Gruska CA, Ysla P, Queiroz A, Nogueira SCDO, Leite MC et al. Effect of different levels of peep on oxygenation during non-invasive ventilation in patients submitted to CABG surgery: randomized clinical trial. Braz J Cardiovasc Surg 2017; 32(4):295-300. 
26. Liu Q, Shan M, Liu J, Cui L, Lan C. Prophylactic Noninvasive Ventilation Versus Conventional Care in Patients After Cardiac Surgery. J Surg Res 2020; 246, 384-394.

27. Laizo A, Delgado FEF, Rocha GM. Complicações que aumentam o tempo de permanência na unidade de terapia intensiva na cirurgia cardíaca. Braz J Cardiovasc Surg 2010;25(2):166-171.

28. Cabrini L, Plumari VP, Nobile L, Olper L, Pasin L, Bocchino S et al. Non-invasive ventilation in cardiac surgery: a concise review. Heart Lung Vessel 2013;5(3):137.

Figure 1. Flowchart related to patient participation in the study.

Table 1. Clinical and surgical characteristics of patients randomized according to the group.

\begin{tabular}{|c|c|c|c|}
\hline Variable & $\begin{array}{l}\text { Conventional NIV } \\
\text { Group }(\mathrm{n}=42)\end{array}$ & $\begin{array}{l}\text { Immediate NIV Group } \\
(\mathrm{n}=37)\end{array}$ & \\
\hline \multicolumn{4}{|l|}{ Gender } \\
\hline Male & $25(60 \%)$ & $21(57 \%)$ & $21(57 \%)$ \\
\hline Female & $17(40 \%)$ & $16(43 \%)$ & $16(43 \%)$ \\
\hline Age (years) & $66 \pm 8$ & $64 \pm 9$ & $64 \pm 9$ \\
\hline $\begin{array}{l}\text { Body Mass Index } \\
\left(\mathrm{kg} / \mathrm{m}^{\mathbf{2}}\right)\end{array}$ & $25 \pm 3$ & $27 \pm 4$ & $27 \pm 4$ \\
\hline \multicolumn{4}{|l|}{ Comorbidities } \\
\hline $\begin{array}{l}\text { Systemic Arterial } \\
\text { Hypertension }\end{array}$ & $28(67 \%)$ & $22(59 \%)$ & $22(59 \%)$ \\
\hline Dyslipidemia & $24(57 \%)$ & $17(46 \%)$ & $17(46 \%)$ \\
\hline Diabetes Mellitus & $19(45 \%)$ & $14(38 \%)$ & $14(38 \%)$ \\
\hline $\begin{array}{l}\text { Acute Myocardial } \\
\text { Infarct }\end{array}$ & $5(12 \%)$ & $3(8 \%)$ & $3(8 \%)$ \\
\hline Sedentary lifestyle & $11(26 \%)$ & $9(24 \%)$ & $9(24 \%)$ \\
\hline Surgery time (mim) & $237 \pm 88$ & $244 \pm 87$ & $244 \pm 87$ \\
\hline $\begin{array}{l}\text { Cardiopulmonary } \\
\text { bypass time (mim) }\end{array}$ & $88 \pm 21$ & $92 \pm 25$ & $92 \pm 25$ \\
\hline $\begin{array}{l}\text { Aortic Clamping } \\
\text { Time (mim) }\end{array}$ & $77 \pm 18$ & $72 \pm 21$ & $72 \pm 21$ \\
\hline $\begin{array}{l}\text { Mechanical } \\
\text { Ventilation time } \\
\text { (hours) }\end{array}$ & $7 \pm 2$ & $8 \pm 3$ & $8 \pm 3$ \\
\hline $\begin{array}{l}\text { Left Ventricular } \\
\text { Ejection Fraction (\%) }\end{array}$ & $58 \pm 6$ & $59 \pm 5$ & $59 \pm 5$ \\
\hline
\end{tabular}

a. Chi-square; b. Independent Student T test.

Table 2. Analysis of blood gases of patients randomized according to the group.

\begin{tabular}{llll}
\hline Variable & Conventional NIV Group $(\mathrm{n}=42)$ & Immediate NIV Group $(\mathrm{n}=37)$ & Difference between groups \\
\hline FIO2 & & & \\
Pre-Intervention & $0,45 \pm 0,11$ & $0,49 \pm 0,09$ & $0,04(-0,1$ to $+0,2)$ \\
Post-Intervention & $0,43 \pm 0,7$ & $0,30 \pm 0,10$ & $0,13(+0,05$ to $+0,22)$ \\
One day later & $0,40 \pm 0,09$ & $0,30 \pm 0,05$ & $0,1(+0,03$ to $+0,3)$ \\
PaO2 (mmHg) & & $90 \pm 14$ & $1(-3$ to +4$)$ \\
Pre-Intervention & $91 \pm 15$ & $80 \pm 16$ & $2(-4$ to +5$)$ \\
Post-Intervention & $82 \pm 12$ & &
\end{tabular}




\begin{tabular}{llll}
\hline Variable & Conventional NIV Group $(\mathrm{n}=42)$ & Immediate NIV Group $(\mathrm{n}=37)$ & Difference between groups $(95 \% \mathrm{I}$ \\
\hline $\begin{array}{l}\text { One day later } \\
\text { PaO2/FIO2 }\end{array}$ & $84 \pm 11$ & $81 \pm 14$ & $3(-7$ to +8$)$ \\
Pre-Intervention & $202 \pm 34$ & $183 \pm 48$ & $19(-11$ to +28$)$ \\
Post-Intervention & $191 \pm 45$ & $266 \pm 29$ & $75(+45$ to +91$)$ \\
One day later & $210 \pm 39$ & $279 \pm 37$ & $69(+33$ to +82$)$ \\
PaCO2 (mmHg) & & & \\
Pre-Intervention & $37 \pm 5$ & $39 \pm 4$ & $2(-4$ to +5$)$ \\
Post-Intervention & $41 \pm 6$ & $42 \pm 3$ & $1(-4$ to +3$)$ \\
One day later & $40 \pm 4$ & $40 \pm 2$ & $0(-2$ to +2$)$ \\
\hline
\end{tabular}

a. Independent Student's t test. FiO2 - Inspired Oxygen Fraction; PaO2 - Arterial oxygen pressure; PaCO2

- Blood pressure of carbon dioxide.

Table 3. Functional results of patients randomized according to the group.

\begin{tabular}{lll}
\hline Variable & Conventional NIV Group $(\mathrm{n}=42)$ & Immediate I $^{-}$ \\
\hline FIM Preoperative ICU discharge Delta $^{\mathrm{b}}$ Hospital discharge Delta $^{\mathrm{c}}$ & $125 \pm 1111 \pm 314 \pm 2121 \pm 24 \pm 2$ & $125 \pm 1115$ \\
6MWT Preoperative Hospital discharge Delta & $417 \pm 36322 \pm 4595 \pm 40$ & $429 \pm 4337$ \\
MRC Preoperative ICU discharge Delta $^{\mathrm{b}}$ Hospital discharge Delta $^{\mathrm{c}}$ & $59 \pm 148 \pm 411 \pm 353 \pm 36 \pm 2$ & $58 \pm 150 \pm$ \\
\hline
\end{tabular}

a. Independent Student's T test; b. Paired Student's T test (preoperative with discharge from the ICU); ç. Paired Student's T test (preoperative with hospital discharge); FIM - Functional Independence Measure; ICU - Intensive Care Unit; 6MWT - Six-minute walk test; MRC - Medical Research Council.

Table 4. Clinical results of patients randomized according to the group.

\begin{tabular}{ll}
\hline Variable & Conventional NIV \\
\hline Complications Pneumothorax Pleural Effusion Atelectasis Severe Respiratory Discomfort Reintubation & $5(12 \%) 22(53 \%)$ \\
In-hospital death & $2(5 \%)$ \\
ICU time (days) & $3 \pm 1$ \\
Hospital stay (days) & $13 \pm 5$ \\
\hline
\end{tabular}

a. Chi-square; b. Independent Student T test.

Para avaliação dos desfechos oxigenação, funcionais e tempo de estadia, intra e intergrupo, foram usados o Teste T de Student pareado e o independe, respectivamente. 